\title{
International evidence on stock returns and dividend growth predictability using dividend yields
}

\author{
Ana Monteiro', \\ (D) https://orcid.org/0000-0002-0663-5336 \\ Email: uc2017203016@student.uc.pt \\ Helder Sebastião ${ }^{1,2}$ \\ (D) https://orcid.org/0000-0002-1743-6869 \\ Email: helderse@fe.uc.pt \\ Nuno Silva ${ }^{1,2}$ \\ (D) https://orcid.org/0000-0002-5687-3818 \\ Email: nunos@fe.uc.pt \\ 1 Universidade de Coimbra, Faculdade de Economia, Coimbra, Portugal \\ 2 Universidade de Coimbra, Centre for Business and Economics Research, Coimbra, Portugal
}

Received on 03.20.2019 - Desk acceptance on 05.02.2019 - $2^{\text {nd }}$ version approved on 01.24.2020 - Ahead of print on 07.10.2020

Associate Editor: Fernanda Finotti Cordeiro Perobelli

\begin{abstract}
This paper examines stock returns and dividend growth predictability using dividend yields in seven developed markets: United States of America (US), United Kingdom (UK), Japan, France, Germany, Italy, and Spain. Altogether, these countries account for around 85\% of the Morgan Stanley Capital International (MSCI) World Index. The use of the long time series with up-to-date data allows the comparison not only between countries, but also across periods, putting into perspective the existence or not of noticeable changes since the 1980's. The majority of the literature on this topic is US-centered. This emphasis on the US is even more pronounced when it comes to examining the relationship between the dividend unpredictability and dividend smoothing. There is also the need to know if the relationships already documented for the post-Second World War (WWII) period still hold during the last three decades, when stock markets were subjected to a high level of turbulence worldwide. The relationship between dividend yields and returns and dividend growth is central to understand the functioning of capital markets, and has considerable implications for capital asset pricing and investment strategies. Overall, the results show that even for developed capital markets there is no clear pattern on the predictive ability of dividend yields on stock returns and dividend growth, instead these relationships seem to be time-dependent and countryspecific. For each country, the predictive ability of the dividend yield is examined in a first-order structural VAR framework by applying bootstrap significance tests and the degree of dividend smoothing is assessed using four partial-adjustment models for the dividend behavior. Additionally, an out-of-sample analysis is conducted using pseudo- $\mathrm{R}^{2}$ and a normal mean squared prediction error (MSPE) adjusted statistic. For the post-WWII period, returns are predictable, but dividends are unpredictable in the US and the UK, while the opposite pattern is observed in Spain and Italy. In Germany, there is some evidence of short-term predictability for both returns and dividends, while in France only returns are predictable. In Japan, neither variable can be forecasted. The dividend smoothing results show that dividends are more persistent in the US and the UK, however, there is no clear connection between dividend smoothness and predictability for the other countries. An important conclusion to retain from the out-of-sample analysis is that the predictability of returns after the WWII, especially present in the US, appeared to have been missing in the last three decades, most probably due to the turmoil experienced by the stock markets during this last period.
\end{abstract}

Keywords: stock return, dividend growth, dividend yield, dividend smoothing, long-run predictability.

Correspondence address

Ana Monteiro

Universidade de Coimbra, Faculdade de Economia

Avenida Doutor Dias da Silva, 165 - CEP 3004-512

Coimbra - Portugal 


\section{INTRODUCTION}

The relationship between dividend yield and returns and dividend growth is a central issue to understand the functioning of capital markets and has considerable implications for capital asset pricing and portfolio investment strategies. This research topic is not new, but still there are no consensual general findings and the discussion on if the main results obtained for the United States of America (US) are applicable to other countries remains quite actual.

For the US, the mainstream of the literature find that the dividend yield has some predictive power on returns, but the predictive power decreases substantially when the dividend growth is the explained variable. A possible explanation proposed in the literature is the dividend smoothing practices undertaken by US firms.

This paper contributes to the existing literature by providing additional international evidence on the predictive power of the dividend yield on returns and dividend growth. More precisely, the paper analysis these relationships for the US, United Kingdom (UK), Japan, France, Germany, Italy, and Spain, using the longest time series available. The aim of the paper is not to construct significant and robust forecasts of returns and dividend growth, which, arguably would be better achieved by including other economic and financial variables as regressors, than just only the dividend yield. This paper is in line with Cochrane (2008), who constructs a joint test for the return and dividend growth predictability using just the dividend yield as the regressor. We also try to figure out if there is some pattern relating dividend smoothness measures and dividend growth predictability, as in Chen, Da and Priestley (2012). Finally, to give more robustness to our results, we conduct an out-of-sample analysis on the forecasting ability of the dividend yields. Although the methodologies used in our paper have been used elsewhere, our paper has some strengths. Namely, it uses up-to-date data including the post 2007 financial crisis period, it compares the results across the most important stock markets in the world and not only for the US or the UK, and it combines in- and out-of-sample analyses.

The remaining of this study is structured into five sections. Section 2 shows a brief literature review on the topic of dividend yield predictive power. Section 3 presents the data and provides some descriptive statistics. Section 4 outlines the basic theoretical concepts on the relationships between dividend yield and returns and dividend growth, the models aimed to assess dividend smoothing, and the methodology used to measure the out-of-sample forecast ability of the dividend yield. Section 5 shows the results and section 6 concludes de paper.

\section{LITERATURE REVIEW}

In the last decades, many authors have studied the predictability of returns and dividend growth by the dividend yield [see, for instance, Ferson and Harvey (1991), Campbell and Ammer (1993), Cochrane (2001, 2008), Lettau and Ludvigson (2005), Lettau and Van Nieuwerburgh (2007), and, more recently, Maio and SantaClara (2015), Golez and Koudijs (2018), Jagannathan and Liu (2019), le Bris, Goetzmann, and Pouget (2019), and Piatti and Trojani (2019)]. The main finding is that the dividend yield strongly predicts stock returns, but it does not predict dividend growth rates. However, this result has been increasingly contested by other papers, showing that dividend yields also predict dividend growth. Campbell and Shiller (1988) report that in the US the dividend-price ratio significantly forecasted one-year dividend growth until 1986. Ang (2002) reaches the same conclusion using data until 2000, however, he also finds that for horizons beyond one year there is no significant dividend growth predictability by the dividend-price ratio. A more recent study by Chen (2009) presents some evidence that the dividend yield did, in fact, predict aggregate US dividend growth in the period before the Second World War (WWII), but this predictive power vanishes away in the post-war period. Binsbergen et al. (2010), using the present-value model framework, show that US dividends are predictable by the whole history of dividend yields. Piatti and Trojani (2019) apply bootstrap tests to the monthly US stock market data for the period 1946 to 2010, and confirm that the postwar return (dividend) predictability evidence in benchmark present-value models is similarly strong (weak) as in standard predictive regression tests, consistently with the 
tale of two periods documented in the literature using standard predictive regressions.

Maio and Santa-Clara (2015) point out that the generalized conviction that variation in dividend yields is exclusively related to expected returns and not to expected dividend growth, although valid for the aggregate stock market, is not true for portfolios of small and value stocks, where dividend yields are related mainly to future dividend changes. The authors show that what explains time variation in the dividend-to-price ratio of small stocks is the predictability of future dividend growth, while in the case of big stocks, it is all about return predictability, especially at longer horizons.

Jagannathan and Liu (2019) show that the US dividend growth in the post-war period is predictable in a model that incorporates information about the corporate payout policy in the dividend growth rate function. The main idea is that high earnings relative to dividends imply that firms have been retaining earnings in the past and thus are expected to pay more dividends in the future. Using US data, the authors show that their model predicts 42.4 to $46.4 \%$ of the variation in annual dividend growth rates between 1946 and 2016 in-sample and 39.5 to $41.3 \%$ of the variation in annual dividend growth rates between 1976 and 2016 out-of-sample.

Most studies on return predictability by the dividend yield (or dividend-price ratio) use US data. This emphasis on the US is even more pronounced when it comes to examining dividend growth predictability [see Paye and Timmermann (2006)]. However, there are some studies on other countries. Campbell (2003) conducts a comprehensive study on asset price determination within a consumption-based framework using international data. He finds some evidence on the dividend growth predictability by the dividend-price ratio in several countries, but not in the US. Engsted and Pedersen (2010) study the dividend yield power in predicting Scandinavian dividend growth. They show that the degree of predictability depends on whether real or nominal variables are used in the analysis.

The different results on the ability of the dividend yield to predict dividend growth put into perspective that this ability is probably conditional to the sample period and it may be country-specific. For instance, Lettau and Ludvigson (2005) provide a potential justification for the absence of predictability of the dividend growth by the dividend-price ratio in the period after the WWII. They conclude that the forecasts of dividends and the forecasts of the excess stock returns are positively correlated with the business cycles. The variations, both in expected returns and in expected dividend growth, are compensated on the dividend-price ratio. They also provide an explanation for the consumption-wealth ratio having a higher power than the log dividend-price ratio in predicting the excess stock market returns over medium-term horizons. Chiang (2008) shows that when the dividends do not capture the relevant future cash flows, the expected dividend growth is not predictable by the dividend yields. They argue that this is due to the flatness of the dividend series, which in turn results from the manipulation and shifts in the financial policies of firms.

Golez and Koudijs (2018) conclude that return predictability from dividend yields has been a robust characteristic of financial markets over the last four centuries, and argue that a possible justification for the absence of dividend predictability is the growing disconnection between earnings and dividends. A lower dividend-to-earnings ratio implies that firms push the eventual payouts to shareholders into the future. Given that expected returns appear to be less persistent than expected dividend growth rates, postponing dividend payments increases the relative sensitivity of dividend yields to shocks in expected returns and reduces the ability of dividend yields to predict dividend growth rates. Le Bris et al. (2019) study the pricing of the Bazacle Company of Toulouse, the earliest documented shareholding corporation, over the 1372 to 1946 period, using share prices and net dividends, showing that the changes in expectations of future dividends explain a significant fraction of price variations. This finding is consistent with the relative importance of cash flow versus discount rate news for individual firms.

Probably, the most established explication for the absence of dividend predictability has to do with the way companies define their dividend policies and more specifically to the practice of dividend smoothing. Chen et al. (2012) report that dividend smoothing can destroy the dividend predictability in a finite sample. In fact, there is a noticeable difference in firms' dividend policies in the US before and after the WWII, with the dividend payouts being much smoother in the post-war period. Thus, the dividend smoothing strategies pursued by US firms after the WWII is a plausible explanation to why in the US dividend growth is predictable before the WWII but not afterwards.

Dividend smoothing literature is heavily weighted towards the US and the international evidence on the relationship between the dividend unpredictability and dividend smoothing is scarce. Usually, authors study separately the two issues and, if there is evidence on 
dividend unpredictability and on dividend smoothing for a particular country, they conclude that probably there is a causal relationship from the later to the former. Rangvid, Schmeling, and Schrimpf (2014) provide a reference study on this relationship for the period 1973 to 2009 , using a comprehensive list of countries. The authors show that dividend predictability is weaker in large and developed markets where dividends are more smoothed, the typical firm is larger, and volatility is lower, hence concluding that the apparent lack of dividend predictability in the US does not uniformly extend to other countries. Our study provides additional evidence on the predictive power of the dividend yield and its relationship with dividend smoothing for seven of the most developed economies in the world using up-to-date data.

\section{DATA DESCRIPTION}

This paper examines the predictability of dividend growth and stock returns in the US, the UK, Japan, France, Germany, Italy, and Spain using the time series of annual stock prices, dividends, and earnings since its availability until 2016. Annual data is used instead of monthly or quarterly data because at these finer frequencies the dividend measurement errors are more severe. Accordingly, annual data has the proper frequency to be used in long run investment strategies with horizons of several years.

For these countries, we collected from the Global Financial Data database the time series of the "total stock returns index", denoted by $R I_{\mathrm{t}}$ "stock prices index" $\left(P_{\mathrm{t}}\right)$, "stocks-dividend yields" $\left(D Y_{\mathrm{t}}\right)$ (in percentage), "stocks - earnings yields" $\left(E / P_{\mathrm{t}}\right)$, and "consumer prices index" $\left(C P I_{\mathrm{t}}\right)$ (the subscript refers to the end of the year $t)$. The data was obtained at the aggregated level of each country general stock index provided by Global Financial Data. The sampling period is different for each country, and for some countries the "stocks-earnings yields" are only available several years after all the other series. Figure 1 shows the sample periods of all the series for each country.

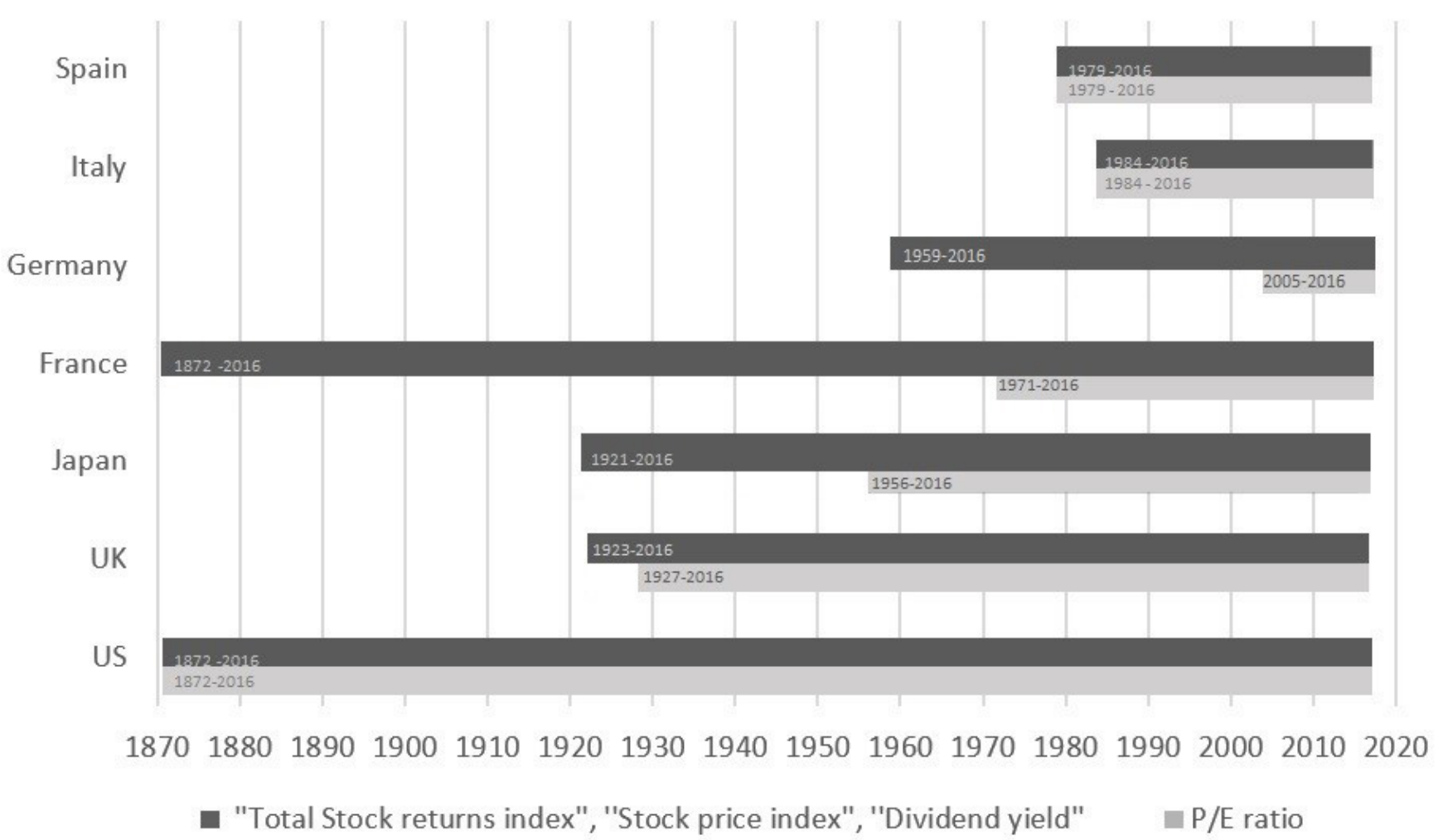

Figure 1 Sample periods for each country

Source: Elaborated by the authors. 
The raw data was then used to compute the appropriate series. The dividend series are obtained as $D_{\mathrm{t}}=\left(D Y_{\mathrm{t}} / 100\right)$ $P_{\mathrm{t}}$, hence the $[\mathrm{G}]$ Prices are measured at the end of the year. yearly dividend growth is given by $D G_{t}=\left(D_{t} / D_{t-1}\right)-1$. The price-earnings ratios are obtained by simply inverting the earning yields series $(P / E)_{\mathrm{t}}=\left((E / P)_{\mathrm{t}}\right)^{-1}$ and the earnings series are computed as $E_{\mathrm{t}}=(E / P)_{\mathrm{t}} P_{\mathrm{t}}$. The arithmetic returns are given by $R_{\mathrm{t}}=\left(R I_{\mathrm{t}} / R I_{\mathrm{t}-1}\right)-1$. All the nominal variables, including the dividend growth and returns, were then deflated by the national consumer price indices (CPI) in order to obtain their real values. The descriptive statistics of the real arithmetic return, real dividend growth, and dividend yield for each country are shown in Table 1. For those countries (US, UK, Japan, and France) where there is data prior to the WWII, the overall sample is divided into two segments: the pre-WWII period, from the start of the samples until 1945, and the post-war period, from 1946-2016.

For the overall sample, considering the US, the UK, Japan, and France, the mean annual return ranges from $5.7 \%$ for France to $8.9 \%$ for Japan, while the mean dividend growth, always lower than the mean return in the respective country, ranges from $0.9 \%$ for Japan to $3.8 \%$ for France. For these countries, the mean return and the mean dividend growth show an increasing pattern from the pre- to the post-WWII period, while their standard deviations (SD) do not show a clear pattern. For the dividend yield, the mean values have decreased while the SD have increased from the first sub-sample to the second sub-sample. The first-order autocorrelation coefficient of returns became negative in the period after the WWII, except for Japan, while this coefficient for the dividend growth has increased in the post-WWII period. The statistics of Germany, Italy, and Spain report to sampling periods after the WWII and hence are better comparable with the post-WWII subsample of the other four countries. The most out of line statistic is the negative correlation coefficient of dividend growth for Italy. The coefficient $\varphi(1)$ shows that the dividend yield is highly persistent, independently of the country or sampling period, ranging from 0.5 (US, pre-WWII period) to 0.90 (Japan, overall sample).

Table 1

Descriptive statistics

\begin{tabular}{|c|c|c|c|c|c|c|c|c|c|}
\hline \multirow[b]{2}{*}{ Variable } & \multicolumn{3}{|c|}{ Overall sample } & \multicolumn{3}{|c|}{ Start of sample to 1945} & \multicolumn{3}{|c|}{ 1946-2016 } \\
\hline & Mean & $\sigma$ & $\varphi(1)$ & Mean & $\sigma$ & $\varphi(1)$ & Mean & $\sigma$ & $\varphi(1)$ \\
\hline \multicolumn{10}{|c|}{ United States of America } \\
\hline$R_{\mathrm{t}}$ & 0.080 & 0.189 & 0.006 & 0.078 & 0.203 & 0.017 & 0.087 & 0.175 & -0.041 \\
\hline$D G_{\mathrm{t}}$ & 0.020 & 0.114 & 0.302 & 0.014 & 0.144 & 0.213 & 0.026 & 0.069 & 0.372 \\
\hline$D Y_{\mathrm{t}}$ & 0.042 & 0.016 & 0.790 & 0.050 & 0.013 & 0.500 & 0.034 & 0.014 & 0.880 \\
\hline \multicolumn{10}{|c|}{ United Kingdom } \\
\hline$R_{\mathrm{t}}$ & 0.079 & 0.204 & -0.107 & 0.069 & 0.143 & 0.298 & 0.083 & 0.218 & -0.171 \\
\hline$D G_{\mathrm{t}}$ & 0.012 & 0.080 & 0.368 & 0.001 & 0.107 & 0.364 & 0.013 & 0.070 & 0.395 \\
\hline$D Y_{\mathrm{t}}$ & 0.045 & 0.014 & 0.582 & 0.046 & 0.009 & 0.619 & 0.046 & 0.015 & 0.567 \\
\hline \multicolumn{10}{|c|}{ Japan } \\
\hline$R_{\mathrm{t}}$ & 0.089 & 0.302 & 0.213 & 0.052 & 0.244 & 0.122 & 0.085 & 0.326 & 0.233 \\
\hline$D G_{t}$ & 0.009 & 0.211 & 0.259 & -0.045 & 0.162 & 0.185 & 0.015 & 0.233 & 0.267 \\
\hline$D Y_{\mathrm{t}}$ & 0.039 & 0.029 & 0.907 & 0.064 & 0.013 & 0.764 & 0.032 & 0.028 & 0.899 \\
\hline \multicolumn{10}{|c|}{ France } \\
\hline$R_{\mathrm{t}}$ & 0.057 & 0.254 & 0.074 & 0.039 & 0.264 & 0.174 & 0.064 & 0.249 & -0.070 \\
\hline$D G_{\mathrm{t}}$ & 0.038 & 0.364 & 0.185 & -0.019 & 0.355 & -0.079 & 0.085 & 0.370 & 0.101 \\
\hline$D Y_{\mathrm{t}}$ & 0.038 & 0.013 & 0.764 & 0.039 & 0.010 & 0.774 & 0.037 & 0.016 & 0.786 \\
\hline \multicolumn{10}{|c|}{ Germany } \\
\hline$R_{\mathrm{t}}$ & 0.070 & 0.227 & -0.077 & - & - & - & - & - & - \\
\hline$D G_{\mathrm{t}}$ & 0.033 & 0.134 & 0.244 & - & - & - & - & - & - \\
\hline$D Y_{\mathrm{t}}$ & 0.033 & 0.010 & 0.683 & - & - & - & - & - & - \\
\hline
\end{tabular}


Table 1

Cont.

\begin{tabular}{|c|c|c|c|c|c|c|c|c|c|}
\hline \multirow[b]{2}{*}{ Variable } & \multicolumn{3}{|c|}{ Overall sample } & \multicolumn{3}{|c|}{ Start of sample to 1945} & \multicolumn{3}{|c|}{ 1946-2016 } \\
\hline & Mean & $\sigma$ & $\varphi(1)$ & Mean & $\sigma$ & $\varphi(1)$ & Mean & $\sigma$ & $\varphi(1)$ \\
\hline \multicolumn{10}{|c|}{ Italy } \\
\hline$R_{\mathrm{t}}$ & 0.069 & 0.260 & 0.112 & - & - & - & - & - & - \\
\hline$D G_{t}$ & 0.040 & 0.220 & 0.169 & - & - & - & - & - & - \\
\hline$D Y_{\mathrm{t}}$ & 0.031 & 0.013 & 0.625 & - & - & - & - & - & - \\
\hline \multicolumn{10}{|c|}{ Spain } \\
\hline$R_{\mathrm{t}}$ & 0.109 & 0.256 & 0.165 & - & - & - & - & - & - \\
\hline$D G_{t}$ & 0.032 & 0.218 & -0.178 & - & - & - & - & - & - \\
\hline$D Y_{\mathrm{t}}$ & 0.051 & 0.034 & 0.808 & - & - & - & - & - & - \\
\hline
\end{tabular}

Notes: denotes the arithmetic real returns and DGt and DY denote the real dividend growth and the dividend yield, respectively. $\sigma$ refers to the standard deviation and $\varphi(1)$ is the first-order autocorrelation coefficient. For those countries where the sample period begins before the Second World War (WWII), the overall sample is partitioned into pre- and post- WWII subsamples. The variables are described in the text.

Source: Elaborated by the authors.

\section{MODELS SPECIFICATIONS}

This section introduces the theoretical concepts and models that are central to the examination of the power of dividend yield in predicting stock returns and dividend growth in different time horizons. Additionally, it presents the concept of dividend smoothing and the models of dividend policy estimated in the next section and introduces a simple but widely recognized methodology to assess the predictive power of dividends out-of-sample.

\subsection{The Dividend Yield Model for Returns and Dividend Growth}

Following Campbell and Shiller (1988), one can derive the following one-period log-linear return approximation:

$$
r_{t+1}=\Delta d_{t+1}+\left(d_{t}-p_{t}\right)-\rho\left(d_{t+1}-p_{t+1}\right)+c, \mathbf{1}
$$

where $r_{t+1}, d_{t+1}$, and $p_{t+1}$ denote the log-return, the logdividend, and log-price of a given stock at period $t+1$, respectively, and $c$ is a linearization constant. Hence, $\Delta d_{t+1}$ is the logarithmic dividend growth rate and

$$
\rho=1 /\left(1+e^{E[d-p]}\right),
$$

where $E[d-p]$ is the expected logarithmic dividend yield that can be simply estimated by the average of the historical logarithmic dividend yield. Therefore, $\rho$ is timeindependent and is typically close to unity.
The present value relationship can be obtained by solving equation 1 forward, taking conditional expectations and imposing a no-bubble condition in the dividend yield, i.e., $\lim _{j \rightarrow \infty} \rho^{j}\left(d_{t+j}-p_{t+j}\right)=0$. Accordingly,

$$
\begin{aligned}
d_{t}-p_{t}= & E_{t} \sum_{j=0}^{\infty} \rho^{j}\left(r_{t+j+1}-\Delta d_{t+j+1}\right) \\
& -c /(1-\rho) .
\end{aligned}
$$

This equation indicates that the current dividend yield can be seen as the discounted value of all future returns $r_{t+j+1}$ and future dividend growth rates $\Delta d_{t+j+1}$, both discounted at a constant rate $\rho$ (minus a constant $c /(1-\rho))$. Equation 3 implies that the dividend yield predicts future returns and/or future dividend growth.

To examine the predictability of returns and dividend growth by the dividend yield, we use the first-order VAR representation of the returns, dividend growth, and dividend yields, as proposed by Cochrane (2008):

$$
r_{t+1}=a_{r}+b_{r}\left(d_{t}-p_{t}\right)+\varepsilon_{t+1}^{r},
$$

$$
\begin{gathered}
\Delta d_{t+1}=a_{d}+b_{d}\left(d_{t}-p_{t}\right)+\varepsilon_{t+1}^{d}, \\
d_{t+1}-p_{t+1}=a_{d p}+\varphi\left(d_{t}-p_{t}\right)+\varepsilon_{t+1}^{d p} .
\end{gathered}
$$


The predictability of returns and dividend growth can be assessed by standard marginal tests. However, Cochrane (2008) highlights that the identity in equation 1 applies to each data point, thus connecting the regression coefficients and the errors in the VAR system (equations 4, 5 and 6). Thus, the projection of equation 1 on $d_{t}-p_{t}$ imply that the regression coefficients must obey to the approximate identity

$$
b_{r}=1-\rho \varphi+b_{d},
$$

and the errors in the VAR are linked via $\varepsilon_{t+1}^{r}=\varepsilon_{t+1}^{d}-\rho \varepsilon_{t+1}^{d p}$.

Assuming that the dividend yield process is not explosive, $\varphi \leq 1 / \rho$, a null hypothesis with both unpredictable returns and unpredictable dividend growth is impossible. In other words, assuming no bubbles, if the dividend yield does not predict the future stock returns (future dividend growth), then it must predict future dividend growth (future stock returns). Hence, under the null hypothesis of no return predictability, $b_{r}=0$, the dividend growth must be predictable, that is $b_{d}$ must be negative (null I). Conversely, if the dividend yield does not predict the future dividend growth, $b_{d}=0$, then it must predict future returns, that is $b_{r}$ must be positive (null II).

\subsection{Dividend Smoothing}

Some authors argue that a possible explanation for the unpredictability of the dividend growth is the guidelines used by companies, aiming to smooth the dividends paid to shareholders, that is, the firms tend to determine the dividend payout taking into account current earnings and past dividend payouts, hence flattening the dividend time series.

The most used dividend smoothness measure is given by

$$
S=\sigma(\Delta d) / \sigma(\Delta e),
$$

where $\sigma(\Delta d)$ is the SD of dividend growth and $\sigma(\Delta e)$ is the SD of earnings growth. A higher value of $S$ means that the dividend smoothness is lower.

In order to investigate the presence of dividend smoothing in our sample, we apply the same framework as Chen et al. (2012). This framework includes four models: the partial-adjustment model for the dividend behavior proposed by Lintner (1956), two variants of this model introduced by Chen et al. (2012), and a fourth model proposed by Marsh and Merton (1987). The Lintner's model and the other two variants show the speed of adjustment (SA) of the dividend payout to a shock in the firm's earnings. The first model is the following:

$$
\text { Lintner: } \Delta D_{t}=\alpha_{0}+\alpha_{1} E_{t}+\alpha_{2} D_{t-1}+u_{t} \text {, }
$$

where $\Delta D_{t}$ is the change in the level of dividends, $E_{t}$ is the level of earnings, and $D_{t-1}$ is the lagged dividend payout. In this model $-\alpha_{2}$ is the so-called SA parameter. A positive shock in the firm's earnings results in an additional dividend payout.

The second model is the following:

$$
\text { Chen - Da - Priestley 1: } \Delta D_{t}=\beta_{0}+\beta_{1} \Delta E_{t}+\beta_{2} \Delta D_{t-1}+u_{t} \text {, }
$$

where $\Delta E_{t}$ is the change in the level of earnings and $\Delta D_{t-1}$ is the change in the dividend payout lagged one period. In this model $1-\beta_{2}$ is the $\mathrm{SA}$, thus $\beta_{2}$ can be interpreted as a measure of dividend smoothness.

The third model is the following:

$$
\text { Chen - Da - Priestley 2: } \Delta D_{t}=\gamma_{0}+\gamma_{1} E_{t}+\gamma_{2} \Delta D_{t-1}+u_{t},
$$

In this model, $\gamma_{2}$ can be interpreted as the dividend smoothness metric. A higher value $\gamma_{2}$ mean a smoother dividend payout.

The fourth model, proposed by Marsh and Merton (1987), is the following:

$$
\text { Marsh - Merton: } \ln \left(\frac{D_{t+1}}{D_{t}}\right)+\left(\frac{D_{t}}{P_{t-1}}\right)=\lambda_{0}+\lambda_{1} \ln \left(\frac{P_{t}+D_{t}}{P_{t-1}}\right)+\lambda_{2} \ln \left(\frac{D_{t}}{P_{t-1}}\right)+u_{t+1}
$$

where $D_{t+1}$ is the next period dividend and $P_{t}$ is the price at $t$. This model allows capturing the intensity of the dividend response to permanent earning changes. Here $\lambda_{1}$ can be interpreted as the dividend smoothness metric, such that a higher $\lambda_{1}$ corresponds to less dividend smoothing.

\subsection{Out-of-Sample Predictive Power}

This subsection describes the procedure adopted to generate forecasts and to evaluate their accuracy. We use an expanding window to predict the returns and dividend growth rates, based on equation 4 and 5, respectively. 
Following Campbell and Thompson (2008), the additional predictive power of the models relative to the historical average can be measured through the pseudo $\mathrm{R}^{2}$ out-ofsample:

$$
\begin{gathered}
R_{O O S, r}^{2}=1-\frac{\sum_{t=t_{o}}^{T}\left(r_{t}-\hat{r}_{t-1}\right)^{2}}{\sum_{t=t_{o}}^{T}\left(r_{t}-\bar{r}_{t-1}\right)^{2}} \text { and } \\
R_{O O S, \Delta d}^{2}=1-\frac{\sum_{t=t_{o}}^{T}\left(\Delta d_{t}-\widehat{\Delta d}_{t-1}\right)^{2}}{\sum_{t=t_{o}}^{T}\left(\Delta d_{t}-\overline{\Delta d}_{t-1}\right)^{2}},
\end{gathered}
$$

where $R_{O O S, r}^{2}$ and $R_{O O S, \Delta d}^{2}$ are the pseudo $\mathrm{R}^{2}$ for the returns and dividend growth rates, $t_{0}$ and $T$ represent the first and last year of the out-of-sample period, $\hat{r}_{t-1}$ and $\widehat{\Delta d}_{t-1}$ are the return and dividend growth model-based predictions using information up to time $t-1$, and $\bar{r}_{t-1}$ and $\overline{\Delta d}_{t-1}$ are the return and dividend growth averages using data up to time $t-1$.

We assess if the models exhibit a higher predictive ability than the historical average using the mean squared prediction errors (MSPE)-adjusted statistic of Clark and West (2007). This test is an approximately normal modified version of the MSPE statistic, which the authors show to be undersized. Its null hypothesis stipulates that the MSPE of both the model and the historical average are equal, whereas, according to the alternative hypothesis, the model predictions are more accurate. The most convenient way to implement this one-sided test is to compute

$$
\begin{gathered}
\hat{f}_{r, t}=\left(r_{t}-\bar{r}_{t-1}\right)^{2}-\left[\left(r_{t}-\hat{r}_{t-1}\right)^{2}-\left(\bar{r}_{t}-\hat{r}_{t-1}\right)^{2}\right] \text { and } \\
\hat{f}_{\Delta d, t}=\left(\Delta d_{t}-\overline{\Delta d}_{t-1}\right)^{2}-\left[\left(\Delta d_{t}-\overline{\Delta d}_{t-1}\right)^{2}-\left(\Delta d_{t}-\overline{\Delta d}_{t-1}\right)^{2}\right],
\end{gathered}
$$

and then regress $\hat{f}_{r, t}$ and $\hat{f}_{r, t}$ on a constant and use the resulting $t$-statistics for a 0 coefficient. The null hypotheses of equal predictive ability are rejected at the $5 \%$ confidence level, if the $t$-statistics exceed 1.645 (one-sided test).

\section{EMPIRICAL RESULTS}

This section presents the estimation results of the models presented before. The VAR systems are estimated by ordinary least squares (OLS). Notice, however, that the VAR errors should be serially uncorrelated, but may present significant cross-correlations, hence the OLS estimators of $b_{r}, b_{d}$, and $\varphi$ are consistent but biased in small samples.
Accordingly, in this framework, hypotheses testing should be conducted using computing intensive methods, such as bootstrap resampling or Monte Carlo simulation. Table 2 presents the results from the $\operatorname{VAR}(1)$, equations 4, 5 and 6, for overall samples of the seven countries under scrutiny

\begin{tabular}{|c|c|c|c|c|c|c|c|c|c|c|c|c|}
\hline & \multirow[b]{2}{*}{$\widehat{\boldsymbol{\rho}}$} & \multirow[b]{2}{*}{ Variable } & \multirow[b]{2}{*}{$\widehat{b}_{r}, \widehat{b}_{d}, \widehat{\varphi}$} & \multirow[b]{2}{*}{$\sigma$} & \multirow[b]{2}{*}{$P m$} & \multicolumn{7}{|c|}{ Corr. of residuals } \\
\hline & & & & & & PC & $R^{2}$ & $r$ & $\Delta d$ & $d-p$ & $\widetilde{b}_{d}$ & $\widetilde{b}_{r}$ \\
\hline \multirow{3}{*}{$\begin{array}{l}\text { United } \\
\text { States of } \\
\text { America }\end{array}$} & 0.963 & $r$ & 0.057 & 0.035 & 0.178 & 0.002 & 0.017 & 0.18 & 0.21 & -0.83 & & 0.146 \\
\hline & & $\Delta d$ & -0.088 & 0.027 & 0.000 & 0.000 & 0.102 & & 0.11 & 0.37 & -0.146 & \\
\hline & & $d-p$ & 0.887 & 0.040 & - & - & 0.783 & & & 0.20 & & \\
\hline \multirow{3}{*}{$\begin{array}{l}\text { United } \\
\text { Kingdom }\end{array}$} & 0.958 & $r$ & 0.233 & 0.082 & 0.011 & 0.000 & 0.095 & 0.19 & 0.26 & -0.92 & & 0.070 \\
\hline & & $\Delta d$ & -0.068 & 0.030 & 0.143 & 0.126 & 0.056 & & 0.08 & 0.15 & -0.070 & \\
\hline & & $d-p$ & 0.734 & 0.092 & - & - & 0.536 & & & 0.19 & & \\
\hline \multirow{3}{*}{ Japan } & 0.973 & $r$ & 0.041 & 0.031 & 0.435 & 0.133 & 0.013 & 0.32 & 0.73 & -0.58 & & 0.067 \\
\hline & & $\Delta d$ & -0.024 & 0.031 & 0.093 & 0.003 & 0.008 & & 0.25 & 0.10 & -0.067 & \\
\hline & & $d-p$ & 0.959 & 0.031 & - & - & 0.947 & & & 0.23 & & \\
\hline
\end{tabular}
using real variables (deflated by the inflation rate).

Table 2

VAR parameter estimates and null hypotheses for the overall samples 
Table 2

Cont.

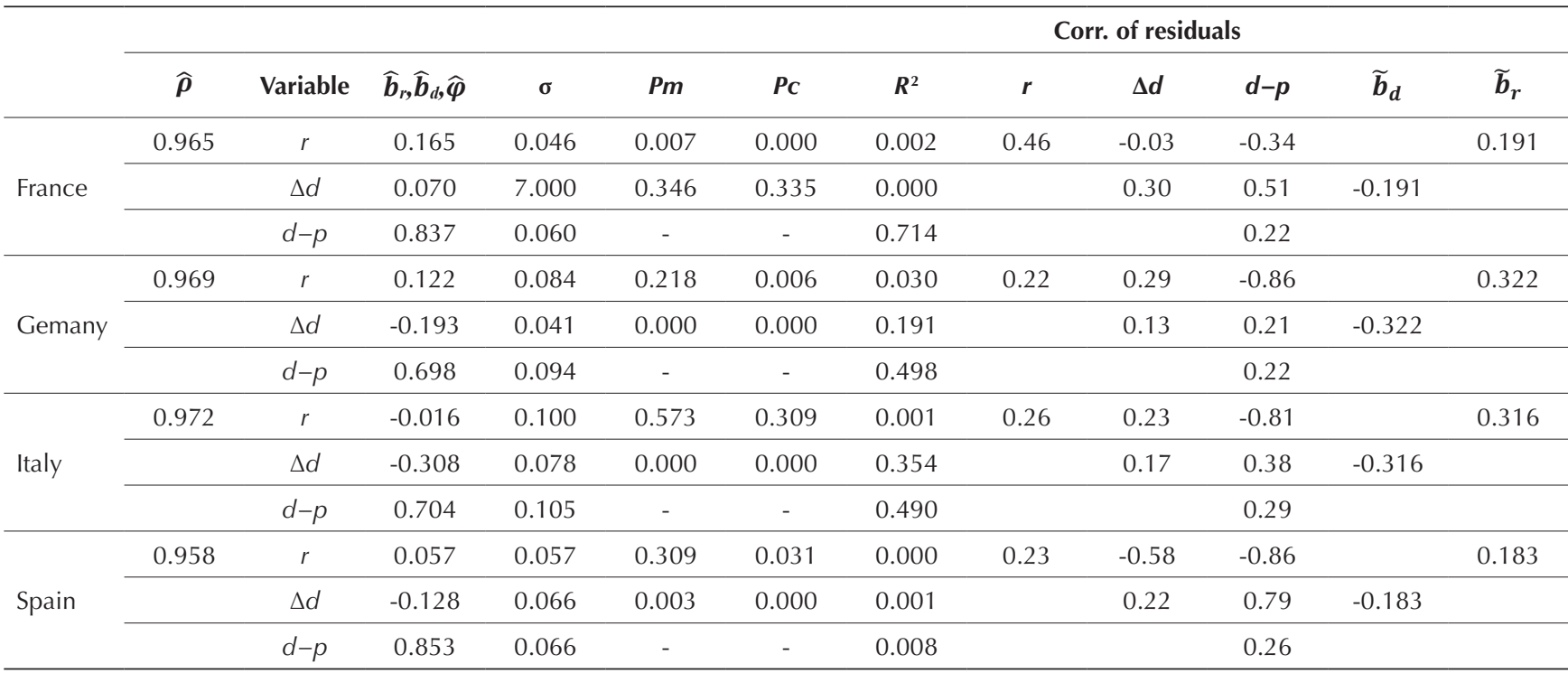

Notes: For each country, the VAR(1) - equations 4, 5, and 6 - is estimated using real returns and dividend growth for the overall sample (see Table 1 on the sample periods for each country). $\hat{\rho}$ is computed according to equation 2, $\sigma$ is the heteroscedasticityconsistent standard errors of the coefficients (White, 1980), the column "Corr. of Residuals" refers to the matrix, where the elements in the diagonal are the standard deviations and the elements off-diagonal are the cross-correlations of residuals, and Pm and $P_{C}$ are probabilities obtained by the Monte Carlo simulations of the system given by equations 4, 5, and 6, considering $\varphi=\hat{\varphi}$, as in Cochrane (2008). These probabilities were obtained from 10,000 simulations of the joint distribution of $\left\{b_{r}\right.$, $\left.b_{d}\right\}$. For the returns rows, $P$ m is given by $\operatorname{prob}\left(b_{r}>\hat{b}_{r} \mid b_{r}=0\right)$ and $P C$ is given by $\operatorname{prob}\left(b_{r}>\hat{b}_{r}, b_{d}>\hat{b}_{d} \mid b_{r}=0\right)$. For the dividend-growth rows, $P m$ is given by $\operatorname{prob}\left(b_{d}<\hat{b}_{d} \mid b_{d}=0\right)$ and $P_{C}$ is given by $\operatorname{prob}\left(b_{d}<\hat{b}_{d}, b_{r}<\hat{b}_{r} \mid b_{d}=0\right)$. The last columns $\left(\tilde{b}_{r}\right.$ and $\left.\tilde{b}_{d}\right)$ are the values of the parameters implied by the identity $b_{r}=1-\hat{\rho} \hat{\varphi}+b_{d^{\prime}}$, where $\hat{\varphi}$ is the sample estimate and $\hat{\rho}$ is value in the second column under the null I, such that $b_{r}=0$, and under the null II, such that $b_{d}=0$, respectively. Hence, $\tilde{b}_{r}=-\tilde{b}_{d}$ are the point estimates under the corresponding null hypotheses.

Source: Elaborated by the authors.

As expected, the constant discount factor $(\rho)$ is close to unity, ranging from 0.958 for the UK and Spain to 0.973 for Japan. The coefficient $\varphi$ for the dividend yield equation is quite high but below unity, ranging from 0.698 for Germany to 0.959 for Japan, showing a higher degree of persistence in the dividend yield process. All the estimates of $\varphi$ are significant at the $1 \%$ level and the dividend yield equation has the highest $R^{2}$ for all countries. In absolute terms, these coefficients of determination are high, except for Spain, where $R^{2}=0.008$. The coefficients for the returns and dividend growth equations, i.e., $\hat{b}_{r}$ and $\hat{b}_{d}$ have the expected signs, except for France, where $\hat{b}_{d}>0$, and Italy, where $\hat{b}_{r}<0$. The proportion of the variability of the oneperiod-ahead dividend growth explained by the dividend yield is only marginally lower than the corresponding proportion for the one-period-ahead return for the UK, Japan, and France. So there is evidence that the dividend growth is more predictable by the dividend yield than returns only for the US, Germany, and Italy.

The column labelled $\mathrm{Pm}$ in Table 2 exhibits the p-values corresponding to the null hypothesis of no return predictability and no dividend growth predictability, based on a single parameter, whereas Pc presents the results from the Cochrane (2008) joint test. The traditional test $(\mathrm{Pm})$ reveals that returns are only predictable in the UK and France, which corroborates the findings in Cochrane (2008) that this test lacks power to detect return predictability. The joint test is able to reject the null hypothesis of no predictability, at the $5 \%$ significance level for all the countries, except Japan and Italy. Regarding the dividend growth, the single parameter test rejects the null hypothesis for the US, Germany, Italy, and Spain. According to the joint test, this hypothesis is rejected for an additional country, Japan.

The columns 8 to 10, labelled "Corr. of residuals", present the SD of the residuals on the diagonal and the cross-correlations off the diagonal. The return SD range from 0.18 , for the US, to 0.46 , for France. The unusually high return SD for France may be explained by the turbulent period during the WWII. The residuals of the dividend growth equation show a similar pattern: they are higher for France and Japan than for the remaining 
countries. The errors for the return and dividend yield equations are negatively correlated for all the countries, but the absolute values of the correlations for Japan and France are considerably lower than the ones for the remaining countries. This is important because the negative correlation between these errors generates a negative correlation between the estimates $b_{r}$ and $\varphi$, which increases the power of the joint test relative to the marginal one-sided test. The return and dividend growth errors are positively correlated for all the countries, except France and Spain. This phenomenon and the unexpected coefficient in the dividend growth equation can be seen as "red flags" for the case of France.
The lack of return and dividend growth predictability may be attributable to dividend smoothing practices and stock repurchases, as has been pointed out by Cochrane (2008), among others. That is, if prices move today in response to dividend news several years into the future, then this information would not be captured by the 1-year VAR presented in equations 4, 5 and 6 because of these news would not be reflected in next year's dividend. In order to address this issue, we tested if the long-horizon returns and dividend growth rates can be forecasted based on the dividend yield. These results are presented in tables 3 and 4 , respectively. These tables also present the results for the two sub-samples, i.e., pre- and post-WWII.

Table 3

Multi-period regressions for the returns

\begin{tabular}{|c|c|c|c|c|c|c|c|c|c|c|}
\hline & \multirow[b]{2}{*}{ k } & \multicolumn{3}{|c|}{ Overall sample } & \multicolumn{3}{|c|}{ Pre-WWII } & \multicolumn{3}{|c|}{ Post-WWII } \\
\hline & & $\widehat{\boldsymbol{b}}_{r, k}$ & $\boldsymbol{P}_{\mathrm{c}}$ & $R^{2}$ & $\widehat{\boldsymbol{b}}_{r, k}$ & $\boldsymbol{P}_{\mathrm{c}}$ & $R^{2}$ & $\widehat{\boldsymbol{b}}_{r, k}$ & $P_{\mathrm{c}}$ & $R^{2}$ \\
\hline \multirow{5}{*}{$\begin{array}{l}\text { United } \\
\text { States of } \\
\text { America }\end{array}$} & 1 & 0.057 & 0.002 & 0.016 & 0.081 & 0.050 & 0.011 & 0.100 & 0.000 & 0.078 \\
\hline & 5 & 0.267 & 0.000 & 0.066 & 0.543 & 0.009 & 0.132 & 0.393 & 0.000 & 0.262 \\
\hline & 10 & 0.458 & 0.000 & 0.142 & 0.622 & 0.020 & 0.199 & 0.737 & 0.005 & 0.467 \\
\hline & 15 & 0.642 & 0.004 & 0.216 & 0.808 & 0.046 & 0.266 & 0.971 & 0.015 & 0.582 \\
\hline & 20 & 0.775 & 0.005 & 0.284 & 0.756 & 0.082 & 0.360 & 1.367 & 0.008 & 0.553 \\
\hline \multirow{5}{*}{$\begin{array}{l}\text { United } \\
\text { Kingdom }\end{array}$} & 1 & 0.233 & 0.000 & 0.095 & -0.079 & 0.080 & 0.012 & 0.270 & 0.000 & 0.271 \\
\hline & 5 & 0.770 & 0.000 & 0.081 & 1.050 & 0.346 & 0.096 & 0.724 & 0.000 & 0.434 \\
\hline & 10 & 0.967 & 0.000 & 0.076 & 0.175 & 0.767 & 0.057 & 1.023 & 0.000 & 0.654 \\
\hline & 15 & 1.159 & 0.000 & 0.093 & 1.467 & 0.331 & 0.051 & 1.172 & 0.000 & 0.618 \\
\hline & 20 & 1.173 & 0.003 & 0.165 & 0.076 & 0.844 & 0.050 & 1.242 & 0.005 & 0.536 \\
\hline \multirow{5}{*}{ Japan } & 1 & 0.041 & 0.133 & 0.013 & 0.557 & 0.076 & 16.65 & 0.041 & 0.098 & 0.003 \\
\hline & 5 & 0.170 & 0.154 & 0.038 & 1.761 & 0.182 & 9.014 & 0.324 & 0.108 & 0.057 \\
\hline & 10 & 0.245 & 0.249 & 0.176 & 2.693 & 0.165 & 11.40 & 0.544 & 0.175 & 0.089 \\
\hline & 15 & 0.299 & 0.318 & 0.216 & 1.511 & 0.311 & 36.70 & 0.699 & 0.238 & 0.211 \\
\hline & 20 & 0.293 & 0.415 & 0.249 & 6.607 & 0.027 & 1.510 & 0.794 & 0.313 & 0.318 \\
\hline \multirow{5}{*}{ France } & 1 & 0.165 & 0.000 & 0.002 & 0.169 & 0.000 & 0.040 & 0.198 & 0.000 & 0.046 \\
\hline & 5 & 0.643 & 0.007 & 0.140 & 0.878 & 0.000 & 0.040 & 0.688 & 0.016 & 0.186 \\
\hline & 10 & 0.565 & 0.117 & 0.107 & 1.024 & 0.012 & 0.056 & 0.619 & 0.106 & 0.104 \\
\hline & 15 & 0.621 & 0.131 & 0.064 & 0.926 & 0.003 & 0.065 & 0.658 & 0.092 & 0.028 \\
\hline & 20 & 0.807 & 0.100 & 0.054 & 0.029 & 0.002 & 0.113 & 0.817 & 0.090 & 0.004 \\
\hline \multirow{5}{*}{ Gemany } & 1 & 0.122 & 0.006 & 0.000 & - & - & - & - & - & - \\
\hline & 5 & 0.656 & 0.007 & 0.001 & - & - & - & - & - & - \\
\hline & 10 & 0.557 & 0.076 & 0.004 & - & - & - & - & - & - \\
\hline & 15 & 0.866 & 0.092 & 0.007 & - & - & - & - & - & - \\
\hline & 20 & 1.260 & 0.048 & 0.006 & - & - & - & - & - & - \\
\hline \multirow{5}{*}{ Italy } & 1 & -0.016 & 0.309 & 0.000 & - & - & - & - & - & - \\
\hline & 5 & -0.102 & 0.718 & 0.000 & - & - & - & - & - & - \\
\hline & 10 & 0.100 & 0.755 & 0.001 & - & - & - & - & - & - \\
\hline & 15 & 0.883 & 0.245 & 0.003 & - & - & - & - & - & - \\
\hline & 20 & 0.123 & 0.669 & 0.004 & - & - & - & - & - & - \\
\hline
\end{tabular}


Table 3

Cont.

\begin{tabular}{|c|c|c|c|c|c|c|c|c|c|c|}
\hline & \multirow[b]{2}{*}{ k } & \multicolumn{3}{|c|}{ Overall sample } & \multicolumn{3}{|c|}{ Pre-WWII } & \multicolumn{3}{|c|}{ Post-WWII } \\
\hline & & $\widehat{\boldsymbol{b}}_{r, k}$ & $P_{\mathrm{c}}$ & $R^{2}$ & $\widehat{\boldsymbol{b}}_{r, k}$ & $\boldsymbol{P}_{\mathrm{c}}$ & $R^{2}$ & $\widehat{\boldsymbol{b}}_{r, k}$ & $P_{c}$ & $R^{2}$ \\
\hline \multirow{5}{*}{ Spain } & 1 & 0.057 & 0.031 & 0.000 & - & - & - & - & - & - \\
\hline & 5 & 0.393 & 0.059 & 0.004 & - & - & - & - & - & - \\
\hline & 10 & 0.472 & 0.155 & 0.005 & - & - & - & - & - & - \\
\hline & 15 & 0.622 & 0.129 & 0.431 & - & - & - & - & - & - \\
\hline & 20 & 0.537 & 0.196 & 0.287 & - & - & - & - & - & - \\
\hline
\end{tabular}

Note: This table presents the results, for each country, of the estimation of the long-horizon returns $\left(\sum_{j=1}^{k} \rho^{j-1} r_{t+j}\right)$ on the log dividend yield $d_{t}-p_{t}$ for the horizon $k=1,5,10,15,20$ years. The full samples for each country are as in Table 1. $P_{c}$ denotes $\operatorname{prob}\left(b_{r}>\hat{b}_{r}, b_{d}>\hat{b}_{d} \mid b_{r}=0\right)$, corresponding to the joint test of Cochrane (2008) for 10,000 Monte Carlo simulations of the $\operatorname{VAR}(1)$ system.

WWII = Second World War.

Source: Elaborated by the authors.

In the full sample, returns are predictable for all time horizons in the US and the UK and they are unpredictable in Japan and Italy. For the remaining countries, the evidence is mixed: the null hypothesis of no predictability is rejected in Spain (one year), France (one and five years), and Germany (one, five and 20 years). In the subsample analysis, there is evidence of an increase in predictability for the US and the UK in the post-WWII period, whereas France exhibits the reverse pattern. For Japan, returns are unpredictable in both sub-periods.
Regarding dividend growth predictability, Table 4 reveals that it is present in Spain at all time horizons, and it is completely absent in Japan and France. Dividends are forecastable at time horizons up to 10 years in the US, at one, two, five, and 20 years in Italy, and only at one year in the UK and Germany. In the subsample analysis, we can observe a decrease in dividend growth predictability for the US and the UK in the post-WWII period, and there is no discernible trend in the ability to forecast dividends in France and Japan.

Table 4

Multi-period regressions for the dividend growth

\begin{tabular}{|c|c|c|c|c|c|c|c|c|c|c|}
\hline & \multirow[b]{2}{*}{ k } & \multicolumn{3}{|c|}{ Overall sample } & \multicolumn{3}{|c|}{ Pre-WWII } & \multicolumn{3}{|c|}{ Post-WWII } \\
\hline & & $\widehat{\boldsymbol{b}}_{d, k}$ & $\boldsymbol{P}_{\mathrm{c}}$ & $R^{2}$ & $\widehat{\boldsymbol{b}}_{d, k}$ & $\boldsymbol{P}_{\mathrm{c}}$ & $R^{2}$ & $\widehat{\boldsymbol{b}}_{d, k}$ & $\boldsymbol{P}_{\mathrm{c}}$ & $R^{2}$ \\
\hline \multirow{5}{*}{$\begin{array}{l}\text { United } \\
\text { States of } \\
\text { America }\end{array}$} & 1 & -0.088 & 0.000 & 0.149 & -0.410 & 0.000 & 0.436 & -0.012 & 0.082 & 0.002 \\
\hline & 5 & -0.131 & 0.001 & 0.039 & -0.368 & 0.007 & 0.058 & -0.012 & 0.094 & 0.007 \\
\hline & 10 & -0.111 & 0.012 & 0.007 & -0.233 & 0.062 & 0.013 & 0.017 & 0.236 & 0.011 \\
\hline & 15 & -0.142 & 0.071 & 0.006 & -0.349 & 0.102 & 0.040 & 0.063 & 0.431 & 0.061 \\
\hline & 20 & -0.084 & 0.193 & 0.003 & -0.286 & 0.165 & 0.011 & 0.262 & 0.860 & 0.125 \\
\hline \multirow{5}{*}{$\begin{array}{l}\text { United } \\
\text { Kingdom }\end{array}$} & 1 & -0.068 & 0.003 & 0.056 & -0.396 & 0.060 & 0.016 & -0.028 & 0.048 & 0.036 \\
\hline & 5 & 0.053 & 0.193 & 0.007 & -0.397 & 0.134 & 0.047 & 0.109 & 0.146 & 0.030 \\
\hline & 10 & 0.142 & 0.382 & 0.006 & -0.537 & 0.042 & 0.052 & 0.203 & 0.486 & 0.064 \\
\hline & 15 & 0.177 & 0.680 & 0.000 & 0.416 & 0.651 & 0.048 & 0.252 & 0.775 & 0.092 \\
\hline & 20 & 0.070 & 0.661 & 0.009 & -0.617 & 0.206 & 0.010 & 0.187 & 0.840 & 0.039 \\
\hline \multirow{5}{*}{ Japan } & 1 & -0.024 & 0.126 & 0.008 & 0.278 & 0.726 & 0.058 & -0.028 & 0.194 & 0.081 \\
\hline & 5 & -0.084 & 0.140 & 0.042 & 1.124 & 0.579 & 0.001 & 0.072 & 0.387 & 0.022 \\
\hline & 10 & -0.204 & 0.127 & 0.118 & 1.753 & 0.678 & 0.010 & 0.011 & 0.362 & 0.004 \\
\hline & 15 & -0.293 & 0.147 & 0.190 & 0.219 & 0.420 & 0.003 & -0.041 & 0.390 & 0.047 \\
\hline & 20 & -0.421 & 0.152 & 0.155 & 5.791 & 0.937 & 0.003 & -0.122 & 0.413 & 0.033 \\
\hline \multirow{5}{*}{ France } & 1 & 0.070 & 0.335 & 0.000 & 0.194 & 0.734 & 0.002 & -0.011 & 0.214 & 0.018 \\
\hline & 5 & -0.142 & 0.329 & 0.000 & 0.008 & 0.500 & 0.001 & -0.201 & 0.182 & 0.000 \\
\hline & 10 & -0.491 & 0.189 & 0.002 & 0.449 & 0.606 & 0.033 & -0.362 & 0.125 & 0.067 \\
\hline & 15 & -0.437 & 0.172 & 0.000 & 1.659 & 0.548 & 0.024 & -0.173 & 0.232 & 0.112 \\
\hline & 20 & -0.289 & 0.203 & 0.006 & 1.582 & 0.465 & 0.025 & -0.087 & 0.435 & 0.096 \\
\hline
\end{tabular}


Table 4

Cont.

\begin{tabular}{|c|c|c|c|c|c|c|c|c|c|c|}
\hline & & \multicolumn{3}{|c|}{ Overall sample } & \multicolumn{3}{|c|}{ Pre-WWII } & \multicolumn{3}{|c|}{ Post-WWII } \\
\hline \multirow{5}{*}{ Germany } & 1 & -0.193 & 0.000 & 0.000 & - & - & - & - & - & - \\
\hline & 5 & -0.153 & 0.084 & 0.002 & - & - & - & - & - & - \\
\hline & 10 & -0.185 & 0.059 & 0.003 & - & - & - & - & - & - \\
\hline & 15 & -0.048 & 0.340 & 0.002 & - & - & - & - & - & - \\
\hline & 20 & 0.104 & 0.703 & 0.001 & - & - & - & - & - & - \\
\hline \multirow{5}{*}{ Italy } & 1 & -0.308 & 0.000 & 0.000 & - & - & - & - & - & - \\
\hline & 5 & -0.948 & 0.000 & 0.000 & - & - & - & - & - & - \\
\hline & 10 & -1.096 & 0.009 & 0.002 & - & - & - & - & - & - \\
\hline & 15 & -0.265 & 0.385 & 0.001 & - & - & - & - & - & - \\
\hline & 20 & -0.617 & 0.048 & 0.002 & - & - & - & - & - & - \\
\hline \multirow{5}{*}{ Spain } & 1 & -0.128 & 0.000 & 0.000 & - & - & - & - & - & - \\
\hline & 5 & -0.500 & 0.009 & 0.002 & - & - & - & - & - & - \\
\hline & 10 & -0.680 & 0.021 & 0.000 & - & - & - & - & - & - \\
\hline & 15 & -0.756 & 0.032 & 0.001 & - & - & - & - & - & - \\
\hline & 20 & -0.990 & 0.009 & 0.000 & - & - & - & - & - & - \\
\hline
\end{tabular}

Note: This table presents the results, for each country, of the estimation of the long-horizon dividend growth rates $\left(\Sigma_{j=1}^{k} \rho^{j-1} \Delta d_{t+j}\right)$ on the log dividend yield $d_{t}-p_{t}$, for the horizon $k=1,5,10,15,20$ years. The full samples for each country are as in Table 1. $P_{c}$ denotes prob $\left(b_{d}<\widehat{b}_{d}, b_{r}<\hat{b}_{r} \mid b_{d}=0\right)$, corresponding to the joint test of Cochrane (2008) for 10,000 Monte Carlo simulations of the $\operatorname{VAR}(1)$ system.

WWII = Second World War.

Source: Elaborated by the authors.

In sum, we cannot conclude that long-horizon tests provide an overwhelming increase in power relative to the one-year tests. This is at odds with Cochrane (2008), who shows that there is a significant increase in power if the time horizon is extended beyond 15 years.

Hereafter, we discuss the results from the various dividend smoothing measures presented in section 4.2. We also analyze the connection between these measures and the predictability results. Note that if the dividends are strongly smoothed, the link between the dividend yield and dividend growth will be broken. Thus, the dividend growth will not be forecastable and $b_{d}$ will tend to 0 . Dividend smoothing also increases the dividend yield autocorrelation $(\varphi)$, which renders its effect on return predictability $\left(b_{r}\right)$ ambiguous (see equation 7 ).

Table 5 reports the estimated dividend behavior models mentioned in the last section and the smoothness parameter. The models are estimated using OLS, with Newey-West corrected standard errors. We had to exclude Germany due to the lack of data.

The first part of this table reveals that dividends have become more stable in the US after WWII, according to all the measures considered: the volatility of dividends relative to earnings decreased from 0.525 to 0.234 , the SA decreased for the models Lintner, Chen-Da-Priestley 1, and Marsh-Merton, and the smoothness parameter increased from 0.249 to 0.374 for Chen-Da-Priestley 2 . Comparing these results with Table 4 , we conclude that, as expected, more dividend smoothing implies less dividend predictability, in accordance with Chen et al. (2012).

In the cross-country comparison, we choose to focus on the post-WWII values for the US and the UK, because for the remaining countries our data does not cover the pre-war period.

The first column in Table 5 shows the volatility of dividend growth relative to the volatility of earnings growth. By this measure, dividends are the most stable in the US (0.234) and the most volatile in Spain (0.968). It is noticeable that the dividend volatility in Spain is more than twice as high as the dividend volatility in every other country. These results corroborate Rangvid et al. (2014), who found that dividends are more stable in larger markets, and Renneboog and Trojanowski (2007) and Denis and Osobov (2008), who showed that dividends are smoother in the US than in France, Germany, and Japan. 


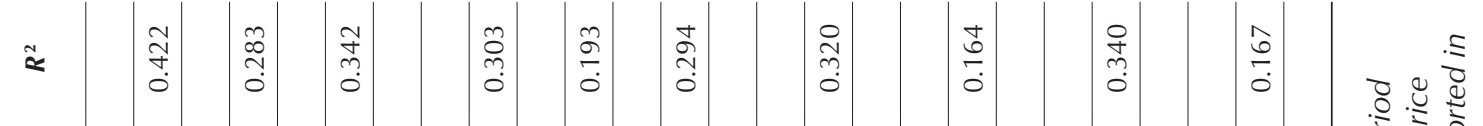

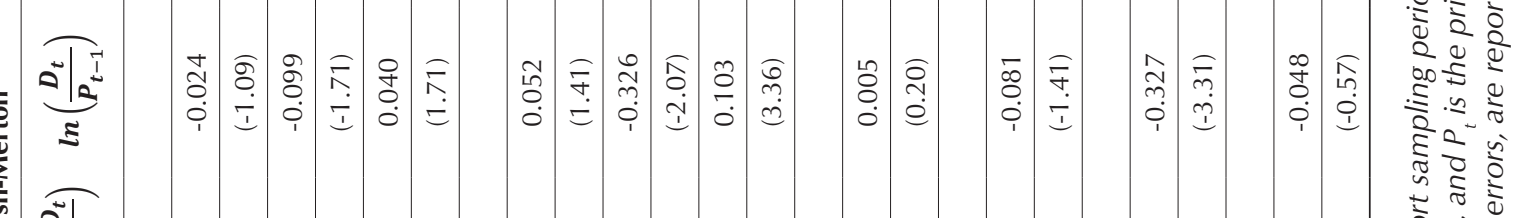

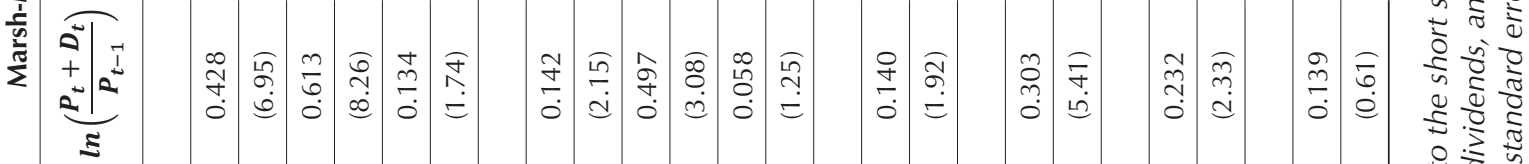

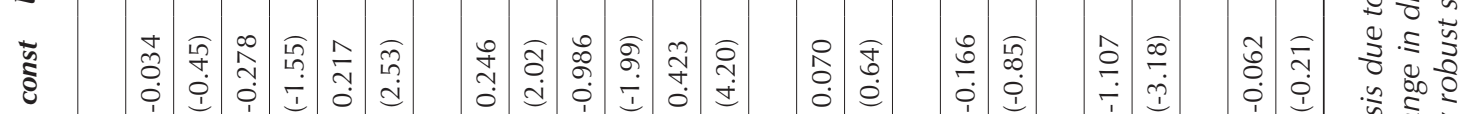

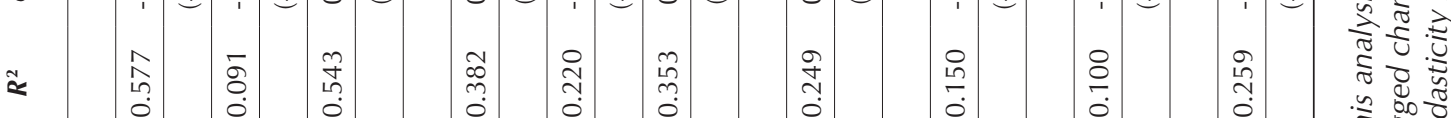

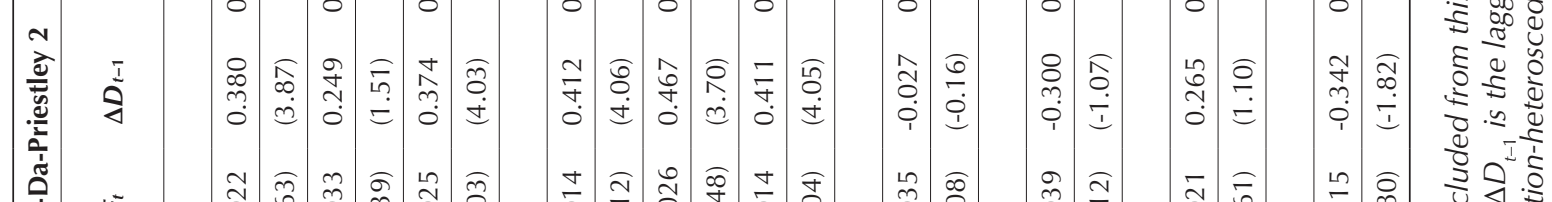

๘ ถ

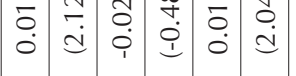

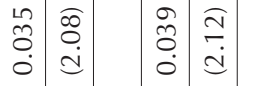

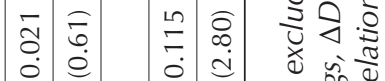

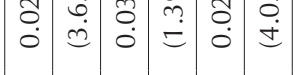

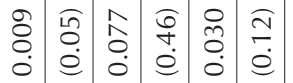

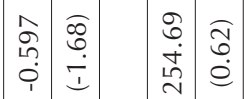

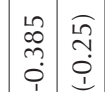

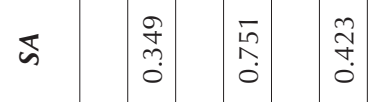

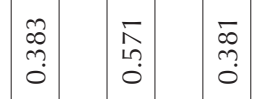

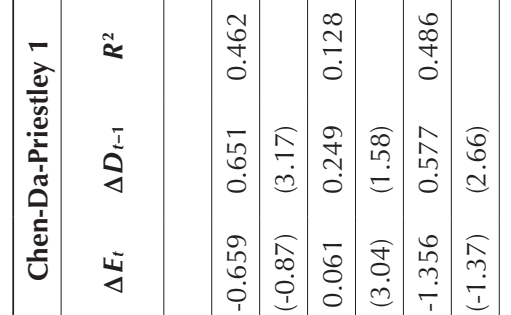

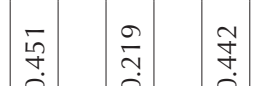

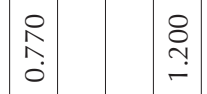

总

8
$\stackrel{0}{0}$
0

$\stackrel{2}{=}$

(n)

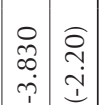

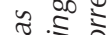

$\begin{array}{llll}0 & 0 & 0\end{array}$

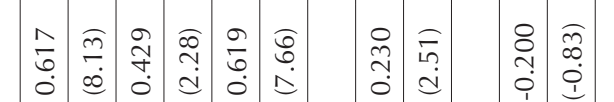

$\circ$

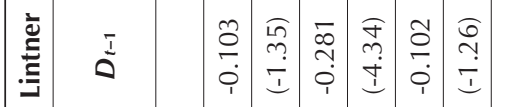

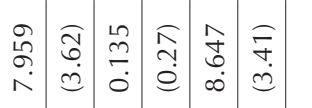

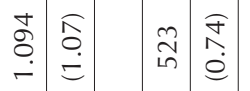

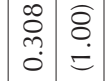

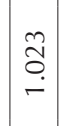

정

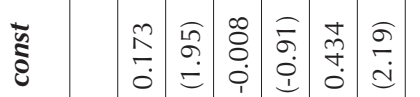

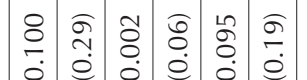

点

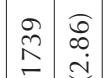

ळ

ฮิ $: \frac{\pi}{2}$

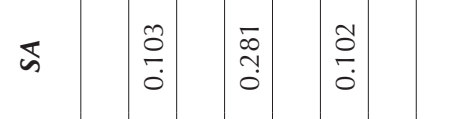

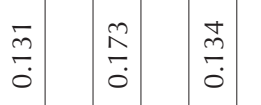

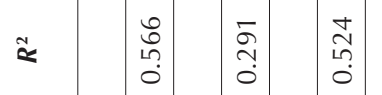

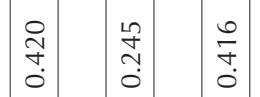

$\frac{\bar{\infty}}{\frac{\infty}{0}}$

0
0
0
0

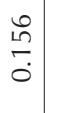

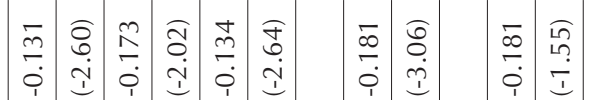

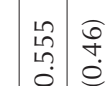

ஸे

व)

ن.

a

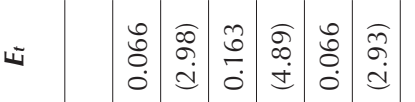

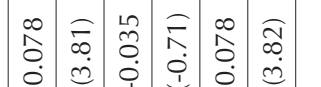

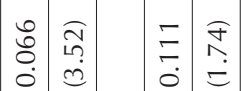

\begin{tabular}{c}
0 \\
\multirow{2}{*}{} \\
$\vdots$ \\
0
\end{tabular}

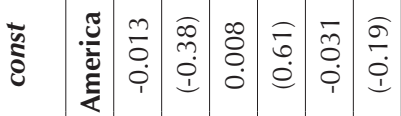

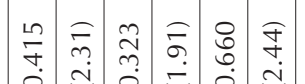

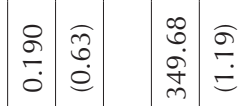

满

สิ ऊับे

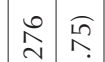

ชิ

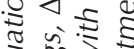

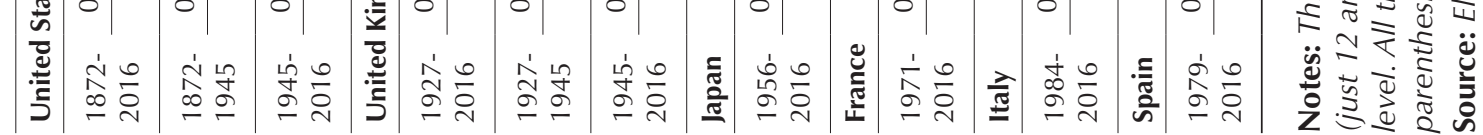


The SA in models Lintner and Chen-Da-Priestley 1 assesses how fast firms adjust their dividends in response to an earnings shock. In Lintner, the SA is the fastest for Italy (0.276), followed by Japan and France (0.181), and the slowest for the US (0.102). According to Chen-DaPriestley 1, dividends are more persistent in the US and the UK than in the other countries. Curiously, French and Spanish companies increase their dividends, following a positive earnings shock, by more than $100 \%$ of the longterm dividend hike implied by the target payout ratio.

In Chen-Da-Priestley 2, the coefficient on the lagged change in dividends is positive and highly significant for the US and the UK, which indicates that firms in these countries engage in strong dividend smoothing. Unexpectedly, for Japan, France, and Spain, this coefficient is negative, but it is not significantly different from 0 at the $5 \%$ significance level.

The coefficient $\lambda_{1}$, in the Marsh-Merton model, captures the response of dividends to permanent earnings changes. US and UK firms are the slowest to react to an earnings shock, as in most other models, while French firms are the fastest ones.

Overall, the different measures of dividend smoothing show some consistency, as they all rank the US and the UK among the countries where dividend persistence is stronger. However, there is some incoherence for the remaining countries. Spain presents the highest dividend volatility and the lowest dividend smoothing according to Chen-Da-Priestley 2, but Lintner shows that this is the second country that most smooths dividends. For France, Chen-Da-Priestley 1 and the Marsh-Merton models place it as the country that least practices dividend smoothing, but its dividend volatility is the second lowest.

These results provide some support to the hypothesis that dividend growth is unpredictable in countries where firms smooth their dividends. Dividend growth is unforecastable after the WWII in the US, and in the UK it is predictable only at the one-year horizon. However, dividends are strongly predictable in Spain and Italy, and unpredictable in France and Japan, even though these countries exhibit a similar degree of dividend smoothing.

Our results regarding the accuracy of the return and dividend growth predictions cover the period from 1900 to 2016, for the US and France, 1946 to 2016 for the UK and Japan, and 1981 to 2016 for Germany. The short data span available for both Spain and Italy prevents the realization of an out-of-sample analysis for these countries.

Figures 2 and 3 exhibit the differences between the cumulative prediction errors based on the historical averages and the models, for the returns and dividend growth rates, respectively.

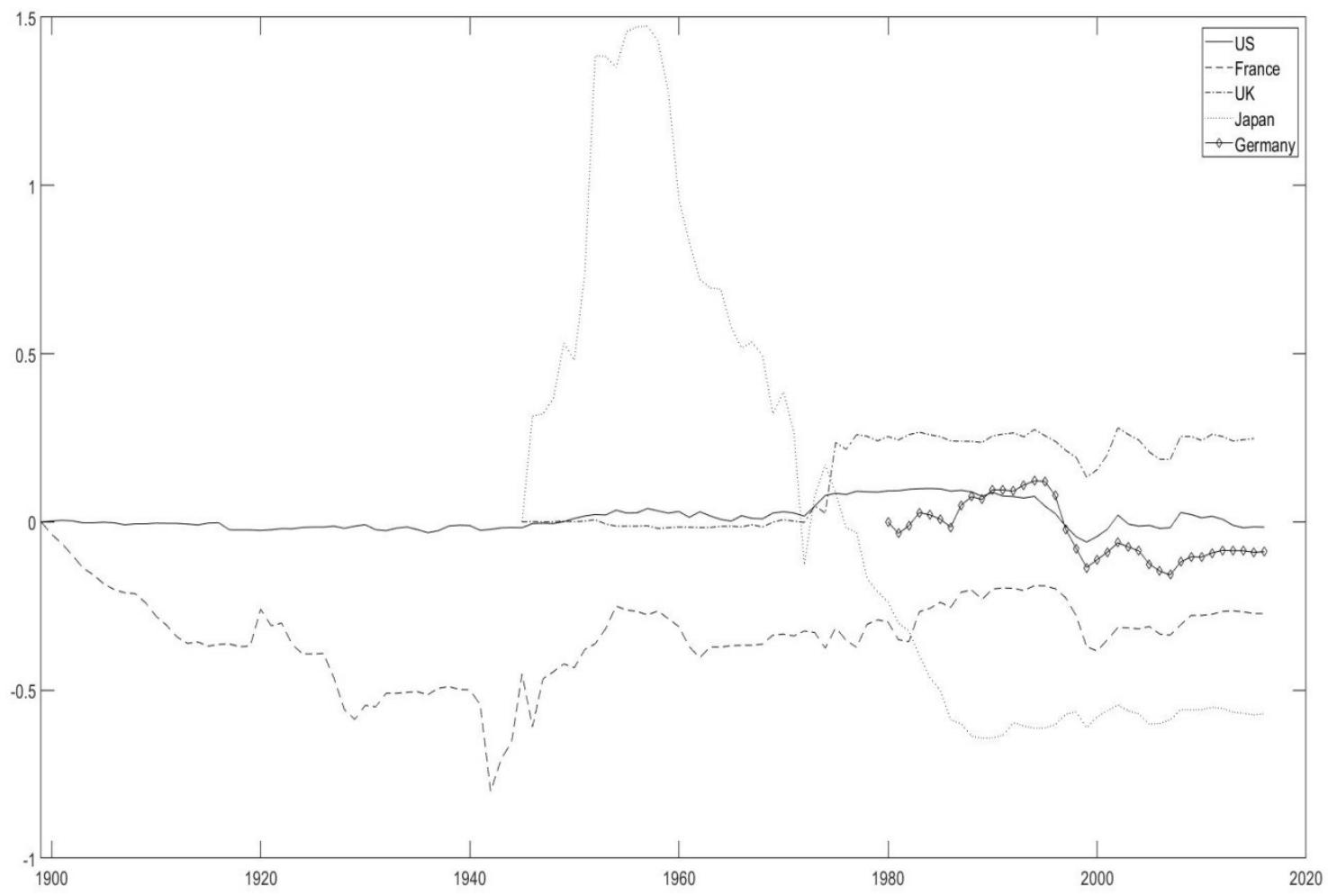

Figure 2 Difference between the cumulative squared prediction errors based on the historical average and the model for the returns

Source: Elaborated by the authors. 


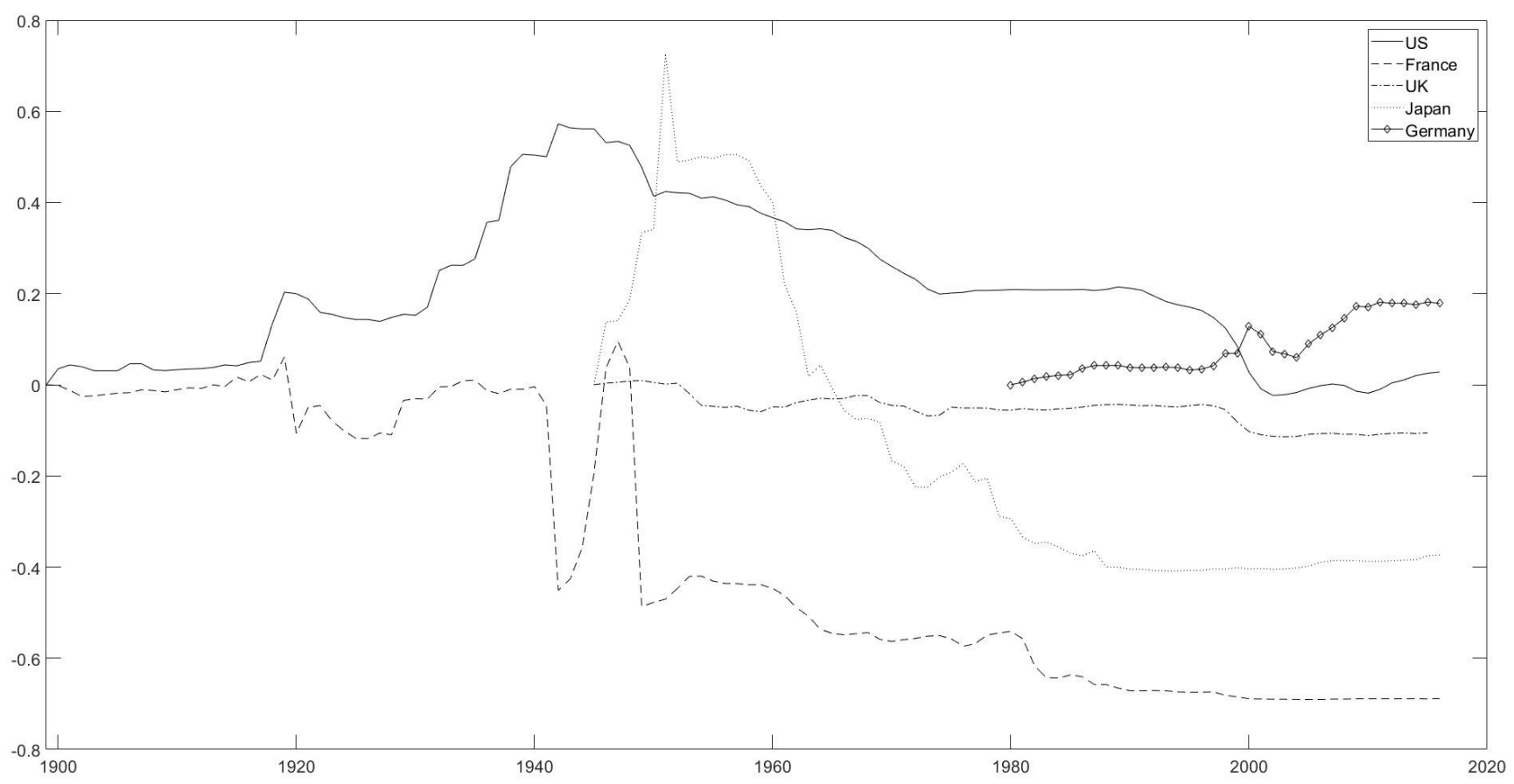

Figure 3 Difference between the cumulative squared prediction errors based on the historical average and the model for the dividend growth

Source: Elaborated by the authors.

Those segments of the lines that present increasing (decreasing) slopes should be interpreted as periods when the models outperform (underperform) the historical averages. Returns are highly predictable in Japan, after WWII until the late fifties, but thereafter the model's performance looks dismal. There is also some evidence of return predictability in France after the WWII and in the UK in the mid-seventies. Figure 3 reveals that the dividend growth rate was predictable in the US, during the first half of the 20th century, in Japan, after the WWII, and in Germany throughout most of the period considered.

Table 6 presents the pseudo $\mathrm{R}^{2}$ out-of-sample and its significance according to the MSPE-adjusted statistic.

Table 6

Pseudo R2 out-of-sample

\begin{tabular}{lcccc}
\hline & Full out-of-sample period & $\mathbf{1 9 0 0 - 1 9 4 5}$ & $\mathbf{1 9 4 6 - 1 9 8 0}$ & $\mathbf{1 9 8 1 - 2 0 1 6}$ \\
\hline United States of America $r$ & -0.003 & -0.007 & $0.098^{* * *}$ & -0.114 \\
$\Delta d$ & $0.019^{* * *}$ & $0.505^{* * *}$ & -2.069 & $-0.988^{* *}$ \\
\hline United Kingdom r & $0.075^{* *}$ & - & 0.1025 & -0.008 \\
$\Delta d$ & -0.305 & - & $-0.288^{*}$ & -0.326 \\
\hline Japan $r$ & $-0.067^{*}$ & - & $-0.037^{* * *}$ & -0.157 \\
$\Delta d$ & $-0.074^{*}$ & - & $-0.067^{* *}$ & -0.124 \\
\hline France $r$ & $-0.039^{*}$ & -0.156 & $0.085^{* *}$ & 0.011 \\
$\Delta d$ & -0.055 & -0.027 & -0.112 & -0.068 \\
\hline Germany $r$ & -0.040 & - & - & -0.040 \\
$\Delta d$ & $0.203^{* * *}$ & - & - & $0.203^{* * *}$ \\
\hline
\end{tabular}

Notes: The full out-of-sample period comprises the years from 1900 to 2016 for the US and France, from 1946 to 2016 , for the UK and Japan, and from 1981 to 2016, for Germany. The significance of the mean squared prediction error (MSPE)-adjusted statistic proposed by Clark and West (2007) to test the models' predictive ability is also shown in the table. Significance at the 1 , 5 , and $10 \%$ levels are denoted by ***, and ***, respectively.

Source: Elaborated by the authors. 
Table 6 shows that the pseudo $\mathrm{R}^{2}$ is positive for the return predictions in the UK (significant at the $5 \%$ level) in the full out-of-sample period. It is also positive and significant, at the $1 \%$ level, for the dividend growth forecasts in the US and Germany. During the first sub-period, the pseudo $\mathrm{R}^{2}$ is only positive for the dividend growth predictability in the US. The subperiod following the WWII shows evidence of return predictability in several countries. The pseudo $\mathrm{R}^{2}$ is positive in the UK, the US, and France, and it is statistically significant at the levels of 1 and $5 \%$ in the last two countries, respectively. In the last period comprised between 1981 and 2016 predictability looks almost absent. The only exception is the dividend growth rate in Germany, which has a positive and highly significant pseudo $\mathrm{R}^{2}$.

\section{CONCLUSION}

The finance literature claims that the dividend yield variation can be explained by news about future returns and future dividends, which means that one can trace price movements back to visible news about dividends or cash flows. In the present study, we confirm some of the much highly reproduced results for the US. In fact, for the US aggregate stock market, the expected future returns account for most of the observed variation in the dividend yields.

We extended the analysis of previous studies by considering six additional countries that, jointly with the US, represent close to $85 \%$ of the Morgan Stanley Capital International (MSCI) World Index. Our results for the post-WWII period reveal that returns are predictable in the US and the UK, but dividends are unpredictable, while the opposite pattern is observed in Spain and Italy. In Germany, there is some evidence of short-term predictability for both returns and dividends, while in France only returns are predictable. In Japan, neither variable can be forecasted.

The dividend smoothing results show that dividends are more persistent in the US and the UK than in the remaining countries. The various measures of dividend volatility do not provide a consistent ranking for Japan, France, Italy, and Spain (Germany was excluded from the analysis due to the lack of data). However, we provide mild support to the hypothesis that dividend predictability is lower in countries where dividends are strongly smoothed, as there is no dividend predictability in the US and the UK, where dividend smoothing is strongest, but we cannot establish a clear connection between dividend volatility and predictability for the other countries.

Cross-country comparisons of dividend smoothing measures must be conducted with caution. Different accounting standards across countries may compromise earnings comparability, which adds noise to our estimators of dividend persistence. Besides that, one should point out that our database does not cover the same time span in different countries. Nevertheless, our study provides some novel insights regarding the cross-country analysis between dividend smoothing and predictability and it opens the door to further research that, using a more comprehensive data or more sophisticated methods, can either confirm or disprove them.

An important conclusion to retain from the out-ofsample analysis is that the predictability of returns after the WWII, especially present in the US, appeared to have been missing in the last three decades, most probably due to the turmoil experienced by the stock markets during this last period.

Overall, the results show that, even for developed capital markets, there is no clear pattern on the predictive ability of dividend yields on stock returns and dividend growth, instead these relationships seem to be timedependent and country-specific. 


\section{REFERENCES}

Ang, A. (2002). Characterizing the ability of dividend yields to predict future dividends in log-linear present value models [Working Paper]. Columbia University.

Binsbergen, V., Jules, H., \& Koijen, R. S. (2010). Predictive regressions: A present-value approach. The Journal of Finance, 65(4), 1439-1471.

Campbell, J. Y. (2003). Consumption-based asset pricing. Handbook of the Economics of Finance, 1(2), 803-887.

Campbell, J. Y., \& Ammer, J. (1993). What moves the stock and bond markets? A variance decomposition for long-term asset returns. The Journal of Finance, 48(1), 3-37.

Campbell, J. Y., \& Shiller, R. J. (1988). The dividend yield and expectations of future dividends and discount factors. The Review of Financial Studies, 1(3), 195-228.

Campbell, J. Y., \& Thompson, S. B. (2008). Predicting the equity premium out of sample: Can anything beat the historical average? Review of Financial Studies, 21(4), 1509-1531.

Chen, L. (2009). On the reversal of return and dividend growth predictability: A tale of two periods. Journal of Financial Economics, 92(1), 128-151.

Chen, L., Da, Z., \& Priestley, R. (2012). Dividend smoothing and predictability. Management science, 58(10), 1834-1853.

Chiang, K. (2008). High dividend yield does predict lower dividend growth: A natural experiment. http://dx.doi.org/10.2139/ ssrn.1107192

Clark, T. E., \& West, K. D. (2007). Approximately normal tests for equal predictive accuracy in nested models. Journal of Econometrics, 138(1), 291-311.

Cochrane, J. H. (2001). Asset pricing. Princeton, NJ: Princeton University.

Cochrane, J. H. (2008). The dog that did not bark: A defense of return predictability. Review of Financial Studies, 21(4), 15331575.

Denis, D. J., \& Osobov, I. (2008). Why do firms pay dividends? International evidence on the determinants of dividend policy. Journal of Financial economics, 89(1), 62-82.

Engsted, T., \& Pedersen, T. Q. (2010). The dividend-price ratio does predict dividend growth: International evidence. Journal of Empirical Finance, 17(4), 585-605.
Ferson, W. E., \& Harvey, C. R. (1991). The variation of economic risk premiums. Journal of Political Economy, 99(2), 385-415.

Golez, B., \& Koudijs, P. (2018). Four centuries of return predictability. Journal of Financial Economics, 127(2), 248263.

Jagannathan, R., \& Liu, B. (2019). Dividend dynamics, learning, and expected stock index returns. Journal of Finance, 74(1), 401-448.

le Bris, D., Goetzmann, W. N., \& Pouget, S. (2019). The present value relation over six centuries: The case of the Bazacle Company. Journal of Financial Economics, 132(1), 248-265.

Lettau, M., \& Ludvigson, S. C. (2005). Expected returns and expected dividend growth. Journal of Financial Economics, 76(3), 583-626.

Lettau, M., \& Van Nieuwerburgh, S. (2007). Reconciling the return predictability evidence. Review of Financial Studies, 21(4), 1607-1652.

Lintner, J. (1956). Distribution of incomes of corporations among dividends, retained earnings, and taxes. American Economic Review, 46(2), 97-113.

Maio, P., \& Santa-Clara, P. (2015). Dividend yields, dividend growth, and return predictability in the cross section of stocks. Journal of Financial and Quantitative Analysis, 50(1-2), 33-60.

Marsh, T. A., \& Merton, R. C. (1987). Dividend behavior for the aggregate stock market. Journal of Business, 60(1), 1-40.

Paye, B. S., \& Timmermann, A. (2006). Instability of return prediction models. Journal of Empirical Finance, 13(3), 274315.

Piatti, I., \& Trojani, F. (2019). Dividend growth predictability and the price-dividend ratio. Management Science, 66(1).

Rangvid, J., Schmeling, M., \& Schrimpf, A. (2014). Dividend predictability around the world. Journal of Financial and Quantitative Analysis, 49(5-6), 1255-1277.

Renneboog, L., \& Trojanowski, G. (2007). Control structures and payout policy. Managerial Finance, 33(1), 43-64.

White, H. (1980). A heteroskedasticity-consistent covariance matrix estimator and a direct test for heteroskedasticity. Econometrica, 48(4), 817-838. 